of pathogenic bacteria such as the tetanus bacillus.

3. The vilus itself if not properly prepared, or perhays oceasionally through unavoidable accident may contai. infections organisms. The most important of these are tlie skin cocci which occasion severe local lesions, and the totamus bacillus which has done considerable mischice of late.

\section{REVERSIBILITY OF ENZYMES, AND ITS APPLICATION TO PHYSIOLOGIC AND PATHOLOGIC PROCESSES.*}

\section{H. GIDLON WELLS, M.D.}

CHICAGO.

Ordinary chemical reactions with which we are most familiar are usually considered as occurring in a very definite manner, the addition of one substance to another leading to the formation of one or more new substances. But it is also a fact that if the proper conditions are produced such a reaction can be made to take place in a reverse manner, the resulting substance or substances being made to yield the substances from which they were originally produced. Recent work has developed the fact that enzyme action is also capable of reversibility, so that when proper conditions exist the products of the hydrolytic splitting, if such has been the change, are reunited by the same enzyme that separated them into the original, more complex molecule. This newly observed property is probably destined to explain many important problems in physiology and pathology, and as so far the literature dealing with the subject has been quite closely limited to technical chemical publications it has seemed desirable to review the work so far done, and to discuss the speculations into which it leads.

Schmiedeberg ${ }^{1}$ had a demonstration of the reversibility of enzymes before him twenty years ago, but while observing the facts he did not interpret them as we now should. He observed not only that renal tissue was able to cause benzoic acid and glycocoll to unite when a mixture of these two substances was brought into contact with it, forming hippuric acid, but also that it was capable equally of splitting hippuric acid into benzoic acid and glycocoll. The splitting of hippuric acid he attributed to a ferment which he succeeded in extracting, and which he called histozyme. But he not only did not consider that the histozyme caused the formation of hippuric acid from the two components, but even stated that absence of histozyme was a requirement for this synthesis, which probably was due to some other agency.

The credit for actually appreciating the reversibility of enzyme action belongs to A. C. Hill. ${ }^{2}$ He approached the subject with the express purpose of testing the possibility that enzyme action was reversible, as simpler chemical reactions were known to be. As a suitable object for investigation he selected maltose, because each molecule of this sugar is split up by the enzyme maltase into two molecules of glucose, and not into two dissimilar molecules as is the case in so many hydrolytic cleavages. It was known that when maltase acts upon maltose in solution a certain amount of the sugar is split up into glucose, but not all of it, so that the result is a mixture of maltose and glucose. Hill found that a similar final result was obtained if the maltase

* My attention was first attracted to this most interesting subject by the lectures of Prof. Jacques Loeb, of the University of Chicago.

1. Arch. f. Exp. Path. u. Pharm.. 1881, xiv. 379.

2. Jour. of the Chem. Society, 1898, lxxiil, 634 . was added to a solution of glucose, for then some of the glucose molecules united to form maltose. Here again the reaction was never complete, and further investigations showed that if all conditions were made similar the final result in either case was the formation of a mixture of the two sugars with a certain definite proportion of each kind. In other words, the action of the enzyme terminates when the enzyme-containing solution holds a certain definite proportion of each sugar. If placed at first in a solution of this composition it would cause no changes whatever. Thus it is seen that the action of the enzyme is merely to establish an equilibrium, and it accomplishes this by causing either cleavage or union as the need may be.

Such a reaction may be expressed graphically as follows:

$\mathrm{C}_{12} \mathrm{H}_{22} \mathrm{O}_{11}+\mathrm{H}_{2} \mathrm{O}+$ maltase $\underset{<-2}{\longrightarrow} 2 \mathrm{C}_{6} \mathrm{H}_{12} \mathrm{O}_{6}+$ maltase.

The double arrow indicates that the reaction occurs in either direction. The reaction of histozyme might similarly be expressed:

$\underset{\text { (benzoic acid) }}{\mathrm{C}_{6} \mathrm{H}_{5}-\mathrm{COOH}}+\underset{\text { (glycocoll) }}{\mathrm{NH}_{2}-\mathrm{CH}_{2}-\mathrm{COOH}}+$ histozyme $\stackrel{<}{\longrightarrow}$ $\mathrm{C}_{6} \mathrm{H}_{5}-\mathrm{CO}-\mathrm{NH}-\mathrm{CH}_{2} \mathrm{COOH}+\mathrm{H}_{2} \mathrm{O}+$ histozyme (hippuric acid)

As the enzyme action tends always to bring the solution to an equilibrium, anything interfering with the attainment of an equilibrium will cause a continuance of the action, if needs be, until complete exhaustion of one of the substances. This is what takes place in digestion. The non-absorbable sugar is split up into absorbable sugars which are removed by the circulatory fluids as they pass through the intestinal walls, and as it therefore becomes impessible for an equilibrium to be established, the cleavage continues until all the sugar in the intestine has undergone cleavage and its diffusible products have been absorbed.

\section{LIPASE.}

More recently our knowledge of reversible enzyme action has been enlarged, and its application to biologic problems begun by the valuable work of $\mathbf{J}$. H. Kastle and A. S. Loevenhart ${ }^{3}$ of the State College of Kentucky. Their work was done with lipase, the fat-splitting ferment of the pancreatic juice. For reasons of technica? convenience they utilized ethyl-butyrate, but lipase acts alike on all fats and the results obtained are applicablc to the fats of common food and tissues. They demonstrated that lipase is able not only to split up fat into fatty acid and alcohol, but also to unite the two latter to form fat. Like the action of maltase, the direction of the reaction depends upon the establishment of an equilibrium, and the result is always a mixture of fat. fatty acid and alcohol. For all cases, then, lipase action may be represented by this equation:

Fat+lipase + water $<\geq$ fatty acid+alcohol+lipase.

Through its action on butyric acid and ethyl alcohol they were able to study the occurrence of lipase in places other than the pancreatic juice. It was found to exist widely distributed in the bodv. in the liver, gastric mucous membranes and kidneys. In fact, the pancreas contains far less active lipase than the liver, at least in the hog, for the results obtained with an extract from the liver were nearly three times as great as a corresponding amount of pancreatic extract gave. Of especial importance, as will be seen later, is their demonstration of the presence of lipase in the mucous membrane of the small intestine. None of the tissues they studied

3. Chemical News, 1901 , lxxxiii, Nos. 2150 to 2155 : and also, American Chemical Journal, 1900, xxiv, 491. 
failed to show a considerable lipase activity, but their researches in this direction were not numerous and it remains to be seen if there is any tissue that does not contain lipase. Even if it should be shown that certain tissues are free from this ferment, which is not probable, considering the almost universal distribution of fat, it is certain that no organ is without lipase during life, for Hanriot has shown that blood serum contains a considerable amount of active lipase. However, it is probably quite a different matter whether the ferment is in the celis of an organ or merely in the fluids circulating through it, in so far as its fat metabolism is concerned.

For other enzymes a reversible action is yet to be demonstrated, but there seems no good reason for disbelieving that it is as true for all the others as for histozyme, maltase and lipase. There is much work to be done in this direction, with good prospects for interesting results. Naturally the question suggests itself: If proteolytic enzymes are also reversible may not proteids be synthesized by acting on the products of proteolysis with the enzyme? Certainly if we assume that all enzyme action is reversible many features of metabolic processes become much simplified. And also as recent investigations tend to show the inseparability of all metabolic processes from enzymes, the importance of this added knowledge of the enzyme processes must be apparent. So far as the subject has yet been investigated, however, we are only justified in applying the results to fat metabolism.

\section{FAT METABOLISM}

The history of fat in the body may now be considered to be as follows: The lipase in the stomach does not act, because of the presence of hydrochloric acid. In the intestines lipolysis occurs, with production of a mixture of fat, fatty acid and alcohol-usually glycerin. But as the fatty acid and glycerin are diffusible, while the fat is not, they are separated from the fat by absorption into the wall of the intestine. Hence an equilibrium is not reached in the intestine, so the splitting continues until practically all the fat has been decomposed and the products absorbed. When this mixture of fatty acid and glycerin first enters the cpithelial cells lining the intestines there is no equilibrium, for there is no fat absorbed with them as such. Therefore the lipase, which Kastle and Loevenhart showed was present in these cells, sets about to establish equilibrium by combining them. As a result we have in the cell a mixture of fat, fatty acid and glycerin which will attain equilibrium only when new additions of the two last substances cease to enter the cell. Now another factor also enters, for on the other side of the cell is the tissue fluid, containing relatively little fatty acid and glycerin. Into this the diffusible contents of the cell will tend to pass to establish an osmotic equilibrium, which is quite independent of the chemical equilibrium. This abstraction of part of the cell contents tends to again overthrow chemical equilibrium, there now being an excess of fat in the cell. Of course the lipase will under this condition reverse its action and split the fat it has just built into fatty acid and glycerin. It is evident that these processes are all going on together, and that as the composition of the contents of the intestines and of the blood vessels varies the direction of the enzyme action will also vary. In the blood serum, and perhaps also in the lymphatic fluid, although this has not yet been investigated, there is more lipase which will unite part of the fatty acid and glycerin, and by removing them from the fluid about the cells favor osmotic diffusion from the intestinal epithelium, thus facilitating absorption.

Quite similar must be the process that takes place in the tissue cells throughout the body. In the blood serum bathing them is a mixture of fat and its constituents, probably nearly in equilibrium since lipase accompanies them. If the diffusible substances enter a cell containing lipase, e. $g$., a liver cell, the processes of building and splitting will be quite the same as in the intestinal epithelium. The only difference is that here the fatty acid may be removed from the cell by being utilized by oxidation or some other chemical transformation.

To summarize, it may be stated that throughout the body there is constantly taking place both splitting and building of fat. Fat enters the cells, leaves them, and is utilized only in the form of its acid and alcohol, never as the fat itself. Fat constitutes a resting stage in its own metabolism. The description given above agrees with all known features of fat absorption and utilization. For example, the crowding of the epithelial cells of the intestinal mucosa with minute fat droplets during digestion is now explained as the result of lipogenesis. That fat can be absorbed in the emulsionized state, as the older physiologists considered these droplets indicated, seems physically improbable. Such a conception is now no longer necessary. The fat depots throughout the body serve to maintain the supply to the blood, and contain lipase which here, as elsewhere, maintains an equilibrium.

If proteolytic** enzymes are also reversible, then the phenomena of proteid metabolism are similarly explained. It has long been known that between the time peptones and albumoses escape from the intestines and enter the circulatory fluids they are changed back into proteid. This fact decidedly supports the conception that an enzyme exists in the intestinal epithelium, acting reversibly on proteids just as the lipase does on fats. There is sufficient evidence to assume that so-called proteolytic ferments also are generally distributed throughout the body. Pepsin has been positively demonstrated in muscles, and Salkowski and Jacoby have called attention to a form of self-digestion which occurs in the tissues during life and also after death. termed autolysis, in which the chemical nature of the products of the change indicates a relation to tryptic digestion.

All metabolism, then, may be considered as a continuous attempt at establishment of equilibrium by enzymes, perpetuated by prevention of attainment of actual equilibrium through destruction of some of the participat. ing substances by oxidation or other chemical processes, or by removal from the body or entrance into it of materials which overbalance one side of the equation. The living body, whether unicellular or multicellular, is a vast, unceasing series of chemical reactions.

FATTY METAMORPHOSIS.***

Applying this fact of reversibility of enzymes to the subject of fatty metamorphosis, so-called, some interesting criticisms of recent literature may be made. Very recently C. Hester" made a study of "fatty degeneration" based upon the attempts of some investigators at the Rostock Institute to explain it as due to an increased saturation of the degenerated tissues with fluids from

** The term "proteolytic enzyme" will need to be replaced if it is shown that the enzymes usually referred to under that title have equally splitting and bullding functions. The general term "protease" might be satisfactory.

*** The subject of fat necrosis will not be considered at th's time, pending the results of certain experiments now incomplete.

4. Virchow's Archiv, 1901, cxliv, 293. 
the blood, the increase in these fluids in turn being due to circulatory disturbances. Hester injected olive oil into the muscles and intermuscular fascia of rabbits. It disappeared very quickly from the vicinity of normal active muscles, more slowly when the muscles were inactive. Such wandering cells as were found passing out from the site of the oil deposits contained but little fat. The muscle fibers near the injected fat showed a fatty deposit as a narrow sub-fascial zone, with some isolated fatty fibers throughout the muscle. Thus it is evident that free fat in the tissues may enter the muscle and fascia cells, and presumably other cells. An exactly similar relation was found between fat depots and fatty muscle fibers under diseased conditions in human beings by investigating fatty hearts, fatty eye muscles, and also muscles in a case of exophthalmic goiter. Here the fatty areolar tissue takes the place of the injected oil of the experiments. From his study of the manner of the transfer of fat from the interspaces into the muscle cells Hester was led to make this statement: "There can be no doubt that the fat enters the muscle fibers in a split condition, and within them is again built up into fat. The splitting of the fat is accomplished in the tissue fluids, the building within the cells." He was familiar with Hanriot's demonstration of lipase in blood serum and quite correctly attributed to it the splitting of the fat in the tissue fluids. He did not know how it was again built up in the cells, but states his confidence that it will ultimately be proven that all the cells of the body, except red corpuscles, are capable of fat synthesis. His explanation is quite complete except that he does not account for the step which lipase takes within the muscle cells.

Hester disregarded the other side of the question of fatty metamorphosis, namely, can proteid be changed into fat? This has been thoroughly threshed over by A. E. Taylor, ${ }^{5}$ chiefly from the standpoint of investigations made upon animals by phosphorous poisoning, or by feeding various known fats. He concludes that: 1. Formation of fats out of proteid physiologically has not been demonstrated or made probable. 2. Nor has it been demonstrated under pathologic conditions; there is much evidence against this, and in favor of its being an infiltration or a formation of fats from carbohydrates. In a subsequent publication ${ }^{6}$ he reviews his own experiments with frogs poisoned with phosphorous, in which he failed to find any evidence of conversion of proteid into fat.

Of the work in favor of the view that the so-called fatty degeneration is in reality an infiltration, the most striking is that of Rosenfeld, ${ }^{7}$ which is quoted by Taylor. This investigator found that starved dogs, when fed on mutton fat, deposited a fat of the same composition as the fat of sheep. If such abnormally fattened dogs were again starved and then poisoned with a drug causing fatty degeneration, phloridzin or phosphorous, it was found that the fat in the degenerated liver was mutton fat. Evidently the fat had been transferred from other tissues to the liver, and was not formed there. Moreover, the liver had lost little of its nitrogen. Another investigation showed that a starved bitch, impregnated, and fed on mutton fat, yielded a milk containing mutton fat. Rosenfeld's results may be looked upon as agreeing with what we should expect to occu: through the action of the lipase of the cells and the blood. If a fat rich in stearin is brought to a cell the

5. Amer. Journal of the Medical Sciences. 1899, cxvil, 569

6. Journal of Exper. Medicine, 1899. iv, 399 .

7. Verhandl. d. Cong. Inn. Med.. 1897. lipase will reform it, after dissociation in the blood into a fat of the same composition, irrespective of what fat is most usual in the body of the animal. The reason that each variety of animal has its own type of fat may perchance be sought in a less ready oxidation of that fat, so that it tends to accumulate. After starvation, however, as in Rosenfeld's dogs, when a certain type of fat is provided any accumulation would necessarily at first be of that type.

Rosenfeld may fairly be said to have shown that in poisoning a certain type of fatty change, which is gencrally considered as "fatty degeneration," in contrast to "fatty infiltration," is really an infiltration. This renders it indeed probable that a similar explanation is to be found for so-called fatty degeneration in other pathologic conditions.

However, it has never yet been shown that proteid can not produce fat, any more than it has been shown that it does do so. If in its catabolism cell-proteid produces fatty acids and alcohol then fat will be produced, since in the cells is a ferment capable of uniting them. This much is new, and it offers a possibility to those who seek to show that fat can be formed from proteid. Still it must be observed that among the known decomposition products of proteids are no fatty acids at all comparable to those constituting the ordinary body fats. The nearest approach is in the amido-acids, such as leucin and glycocoll, but none of these contain nearly as many carbon atoms as do oleic, palmitic and stearic acids. We know as yet no enzyme capable of combining lower fatty acids into higher-certainly there is no reason yet shown for assuming that lipase does so; therefore: if proteid is really a source of fat, there must be other agencies at work than any with which we are yet familiar.

It is to be noted that the organ in which fatty metamorphosis is most often and most extensively seen as a pathologic process, the liver, contains the most lipase, so far as the observations of Kastle and Loevenhart have' gone. This is quite comparable with the observation of Loevenhart ${ }^{8}$ that the mammary gland during lactation contains much more lipase than when at rest. It seems, then, that the amount of lipase in the cells bears a direct relation to the amount of fat that will be formed in them. This may be explained by the fact that if an equal amount of fatty acid and glycerin is taken into each of two cells containing different quantities of lipase, fat will be formed more rapidly in the one with the greater amount of lipase. As the fluid bathing the cells is continuously moving from one part of the body to another it maintains nearly a constant composition, so that the amount of acid and glycerin that will diffuse into each cell will depend solely upon the amount already within the cell. Obviously the cell wherein the fatty acid and glycerin have been combined into fat will be in condition to receive more new material than will the other in which they are largely ununited, since the entrance of these substances is simply a matter of osmosis. Hence this fat-laden cell wili continue to add more and more fat. This may indicate the normal mechanism of fat storage in the areolar tissue depots. which are known to contain considerable lipase.

Shall we consider from this that "fatty degeneration" is simply a matter of quantity of enzyme in the abnormal cells? It surely seems strange that a cell injured by toxic, mechanical, or nutritional agencies should possess any increase in lipogenetic power-on the contrary,

8. Proceedings of the Amer. Physiol. Soc.. 1900, xil-xili. 
one would expect the lipase to suffer with the cell. This seems to be the case. A. Poulain ${ }^{9}$ has investigated the lymph glands in health and disease with the following results: 1 . In normal conditions the lipolytic power is the same in the mesenteric glands and in the subcutaneous glands at the same time in the same subject. 2. In intestinal infections the lipolytic activity of the mesenteric glands diminishes greatly compared to the peripheral. 3. The contrary relation is found when the infection is in the area draining into the subcutaneous glands. 4. In generalized infections the lipolytic power is lowered about the same in all the glands of the body. In other words, when the glands are injured by toxic substances their power is decreased. But Martin Jacoby $^{10}$ has found that autolysis, which is evidently it ferment action, is increased in phosphorous poisoning, and it may therefore be that lipase is injured by some poisons and stimulated by others. Study of lipase activity of livers that have been rendered fatty by phosphorous and similar poisons may yield interesting results.

Another factor must also be considered, namely, the process of removal of fat from the cell. This, so far as we know, is accomplished by oxidation. According to recent investigations this oxidation is also an enzyme action. May it not be, then, that poisons cause fatty degeneration only when they are of such a nature that they destroy the ferments that oxidize the fat, and do not destroy the lipase? Under such circumstances the fat equilibrium in the cell would be established when there was chemical equilibrium between the formed fat and the free components, and an osmotic equilibrium between these diffusible substances within the cells and those in the blood stream. Unlike normal conditions there would be no third factor of removal of fatty acid and glycerin by oxidation; this might lead to an accumulation. As agreeing with this idea are: 1. The fact that only certain poisons cause fatty change. 2 . The association of nuclear changes with fatty degeneration, and the demonstrated fact of the importance of the nucleus for processes of oxidation within the cell (Spitzer, ${ }^{11}$ Loeb $^{12}$ ). 3. Besides, as a result of poisoning, fatty change is also a result of circulatory disturbances, as in infarction. Here impaired oxidation is recognized as a factor, and weight is given to this belief by the similarity of the processes in the chronic asphyxia of pernicious anemia and of lung disorders. There is no reason for considering that this fatty change is different from that in poisoning, $i$. e., they both probably indicate impaired oxidation, the one from absence of oxygen, the other perhaps from lack of enzyme to combine the oxygen. A study of both lipase and oxydase activity in normal livers and in fatty livers may determine this question finally.

\footnotetext{
9. Comptes Rend. Soc. Biol,, 1901, liii, 786 .

10. Zeltschr. f. Phys. Chem., 1900, xxx.

11. Pfluger's Archiv, 1897, Ixvii, 615.

12. Arch. f. Entwicklungsmech., 1899, viii, 689 .
}

Treatment of Wandering Spleen.-Ssaweljew describes in the Med. Ohosrcme the successful treatment of a wandering spleen in a boy of 4 who had recently recovered from smallpox. The enlarged organ lay in the umbilical region and was painful on pressure, causing almost constant vomiting. There were also symptoms of intestinal catarrh. Treatment was directer first against the enteritis, after which euchinin was administered in order to reduce the size of the spleen. The spleen was restored to its place and maintained in position by a baudage, while the child was kept on his back in bed. A complete cure was thus attained.

\section{PULMONARY FEARLESSNESS.*}

\author{
W. T. ENGLISH, A.M., M.D. \\ PITTSECRG, $\mathbf{1} \Lambda$.
}

From the earliest records of primitive man there are evidences of a wide range of his fears, and the noble advantages secured through the pedagogy of fear. Ere reason ascended its lofty throne, fear expressed itself through the somatic life, and with a celerity which outruns human thought still continues to protect us against threatening harm, even before we know in what the harmful thing consists. Whether originating in the soma or psyche, and however modified, fear invariably appeals to the sentiency of the breathing apparatus and exalts the pulmonary movements beyond the realms of automatism. Those fears which in primeval days prompted directly the exercise of the pulmonary sentiency or indirectly necessitated excessive activity of the lungs added to the efficiency of these organs by maintaining and cultivating their primary allotment of somatic and neural energy and became factors in the attainment of normal intercourse between the nerves distributed to the breathing apparatus and the higher centers. Hundreds of generations have regarded the respiratory organs with a reverential awe, which is the outgrowth of fear, and the ancients considered the terms "breath" and "breathing" as etymologic equivalents of "soul" and "spirit." From the very nature of his inheritance, man is at birth a pulmophobiac. The first new impulse is inaugurated through fears which are products of primal psychisms and impels the newly born to fill his lungs with air, and as he is but a reflex and automatic organism, these fears gain expression through somatic channels. The teleologic significance of this awakening of the breathing apparatus is emphasized by the oft-repeated and obvious prenatal efforts at selfprotection during that portion of gestation within the range of fetal impressionability. This first betrayal of fear influence upon the pulmonary apparatus on the child's advent into independent existence, is repeated thereafter in consequence of each wavering or irregular action of the lungs. Sleeping or waking, fear guards, protects and dominates respiration, as it does no other function. Throughout the early life of those who have their proper legacy of fear, the threatened pulmonary apparatus startles like a guilty thing, as a result of limitations. Even in the semi-consciousness of dreams respiratory modifications cause the most acute alarms.

The normal child regards closed rooms and confinement within small areas as an alienation from safety. Caves, small apartments, narrow passes and dense forests produce fear effects through respiratory restraint. Fogs, gases, odors, mists, smoke, the barometric fall, each may exert an influence detrimental to perfect pulmonary activities with resulting apprehension. A personal acquaintance with fears which concern the pulmonary apparatus has been the early experience of most of us. The plays adopted usually imply the hidden foe springing upon his victim, or the imitative nature assumes the beasts of prey, and, in the simplest outbursts of juvenile enthusiasm there is an instinctive leaning toward the deep, powerful, dangerous primeval sensations, in which the breath comes in great waves or gulps. If the child were born immune to fear, he would be denied part of his pleasure-giving birthright. During childhood, and later in some cases, there is a continu-

\footnotetext{
* Read at the Fifty-second Annual Meeting of the American Medical Association, in the Section on Hygiene and Sanitary Sci ence, and approved for publication by the Fxecutive Committee of the Section.
} 